\title{
Monitoring response to cytostatic cisplatin in a HER2 $(+)$ ovary cancer model by MRI and in vitro and in vivo MR spectroscopy
}

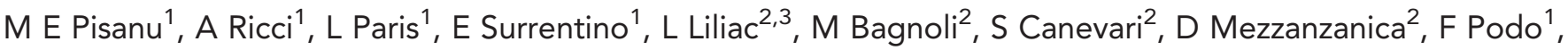 \\ E lorio ${ }^{\star, 1,4}$ and $\mathrm{R}$ Canese ${ }^{\star, 1,4}$ \\ ${ }^{1}$ Department of Cell Biology and Neurosciences, Istituto Superiore di Sanità, Viale Regina Elena 299, 00161 Roma, Italy; \\ 2 Department of Experimental Oncology and Molecular Medicine, Fondazione IRCCS Istituto Nazionale dei Tumori, Via Amadeo \\ 42, 20133 Milano, Italy and 'Department of Histology, University of Medicine and Pharmacy 'Grigore T. Popa', lasi, Romania
}

Background: Limited knowledge is available on alterations induced by cytostatic drugs on magnetic resonance spectroscopy (MRS) and imaging (MRI) parameters of human cancers, in absence of apoptosis or cytotoxicity. We here investigated the effects of a cytostatic cisplatin (CDDP) treatment on ${ }^{1} \mathrm{H}$ MRS and MRI of HER2-overexpressing epithelial ovarian cancer (EOC) cells and in vivo xenografts.

Methods: High-resolution MRS analyses were performed on in vivo passaged SKOV3.ip cells and cell/tissue extracts (16.4 or 9.4 T). In vivo MRI/MRS quantitative analyses (4.7 T) were conducted on xenografts obtained by subcutaneous implantation of SKOV3.ip cells in SCID mice. The apparent diffusion coefficient (ADC) and metabolite levels were measured.

Results: CDDP-induced cytostatic effects were associated with a metabolic shift of cancer cells towards accumulation of MRSdetected neutral lipids, whereas the total choline profile failed to be perturbed in both cultured cells and xenografts. In vivo MRI examinations showed delayed tumour growth in the CDDP-treated group, associated with early reduction of the ADC mean value.

Conclusion: This study provides an integrated set of information on cancer metabolism and physiology for monitoring the response of an EOC model to a cytostatic chemotherapy, as a basis for improving the interpretation of non-invasive MR examinations of EOC patients.

Non-invasive assessment of effects induced by anticancer agents on functional parameters and metabolic profiles of tumour lesions is expected to have an increasing impact on the development and use of personalised therapeutic strategies. Besides detecting changes in glucose and neutral lipid metabolism, magnetic resonance spectroscopy (MRS) contributed to the identification of an altered choline phospholipid metabolism in cancer cells and tissues as a potential source of novel indicators of tumour progression and therapy response (Negendank, 1992; Podo, 1999; Day et al, 2007; Beloueche-Babari et al, 2010; Delikatny et al, 2011; Podo et al, 2011; Sharma et al, 2011; Glunde et al, 2011a, b). In particular, we reported an aberrant phosphatidylcholine (PtdCho) metabolism in human epithelial ovarian cancer (EOC) models in vitro and in vivo (Iorio et al, 2005, 2010; Podo et al, 2011; Canese et al, 2012), in which a substantial accumulation of intracellular phosphocholine (PCho) was detected compared with nontumoral counterparts. An increase of PCho in tumours is commonly interpreted as an indicator of increased membrane turnover in actively proliferating cells.

${ }^{1} \mathrm{H}$ MRS studies on in vivo xenografts and in vitro cancer cells, showed that PCho, the major component of the so-called total choline resonance (tCho) centred at 3.2 p.p.m., may show

\footnotetext{
*Correspondence: Dr E lorio; E-mail: egidio.iorio@iss.it or Dr R Canese; E-mail: rossella.canese@iss.it

${ }^{4}$ These authors contributed equally to this work.
}

Received 31 July 2013; revised 1 November 2013; accepted 7 November 2013; published online 12 December 2013 
substantial decreases after anticancer treatments such as chemotherapy (Morse et al, 2007) and immunotherapy (Proietti et al, 1988), suggesting that tCho may act as a non-invasive biomarker of in vivo cancer response.

The significance of the MRS tCho profile as a biomarker of cancer therapy response has been explored in clinical settings in patients affected by different types of cancer (Payne and Leach, 2006; Glunde et al, 2011b). A reduction of tCho has also been associated with early response in lymphomas (Griffiths et al, 2002); a decrease in the choline/water ratio was detected in brain tumours during temozolomide treatment (Murphy et al, 2004); and a decrease in the $\mathrm{tCho/citrate}$ ratio was detected in prostate cancer in response to hormone-deprivation therapy (Kurhanewicz et al, 1996). Characteristic changes in the signals of aqueous choline phospholipid metabolites (reviewed in Podo (1999)) as well as in MRS-visible mobile lipids (ML) (Blankenberg et al, 1996; Di Vito et al, 2001; Iorio et al, 2003) have been associated with anticancer treatments leading to apoptosis or necrosis.

The reported changes in the tCho profile in cancer lesions are often associated with the cytotoxic effects exerted by chemotherapeutic agents. However, only a limited attention has been so far devoted to evaluate in quantitative terms the effects induced by cytostatic (rather than cytotoxic) treatments on the tCho profile of growth-arrested experimental and clinical tumours. This issue appears particularly relevant, because a number of newly designed targeted therapies may primarily induce cytostatic rather than cytotoxic effects (Garrett and Workman, 1999; Beloueche-Babari et al, 2010). Under these conditions, the use of purely anatomical imaging methods may be seriously limited. An earlier evaluation of treatment response based on drug effects different from anatomical tumour shrinkage could facilitate a timely decision on whether a given therapeutic strategy should be maintained or modified, thus avoiding further exposure of non-responders to unnecessary systemic side effects. Functional assessment of water mobility within a tumour lesion using diffusion-weighted MRI (DWI) methods is a promising tool for an early evaluation of the responsiveness to anticancer treatments, as tissue water diffusion is sensitive to macromolecular and micro-structural changes, which can occur at the cellular level (Thoeny and Ross, 2010; Serkova and Brown, 2012). Preclinical and clinical studies have shown that treatment efficacy can be monitored in a wide variety of tumour types using DWI. Typically, a successful treatment induces early alterations in the water apparent diffusion coefficient (ADC) values of affected tissues. In particular, changes in tumour cellular structures can occur under induction of programmed cell death, which results in a decrease in tumour cellularity, thus causing an increase in the mean tumour ADC value. On the other hand, a drug-induced swelling of tumour cells would produce a transient drop in $\mathrm{ADC}$ values which, on conversion of the targeted tissue to necrosis, would then lead to the formation of areas characterised by elevated $\mathrm{ADC}$ values. In addition, low pre-treatment $\mathrm{ADC}$ values in various types of tumours are often predictive of a better response to chemotherapeutic agents (Thoeny and Ross, 2010).

The use of these non-invasive imaging methods for an early assessment of treatment efficacy may be of particular relevance for those tumours requiring new therapeutic approaches such as EOC, mainly due to advanced stage at diagnosis and inherent or emerging drug resistance (Carter et al, 2013; Sala et al, 2013; Wakefield et al, 2013).

Indeed, the standard treatment for an advanced stage EOC is aggressive primary surgery followed by taxane- and platinumbased therapy. However, cure rates have not shown a substantial improvement even in the chemosensitive setting (Vaughan et al, 2011) and the majority of patients with advanced stage disease is expected to relapse and develop a drug-resistant disease. For these reasons, better therapeutics agents as well as new strategies for monitoring early therapy effects are urgently needed.
In the present study, we compared the in vitro ${ }^{1} \mathrm{H}$ MRS tCho profile of two EOC cell lines, SKOV3 and its in vivo passaged cell variant SKOV3.ip, characterised by different levels of human epidermal receptor 2 (HER2/neu) overexpression and in vivo tumorigenicity. We then investigated the changes induced on the tCho profile of the most tumorigenic of these cell lines, SKOV3.ip, by in vitro exposure to the cytostatic action of cisplatin. We finally evaluated on quantitative bases the capabilities and limitations of in vivo $\mathrm{MR}$ approaches (diffusion-weighted MRI and ${ }^{1} \mathrm{H}$ MRS) in monitoring functional alterations induced in SKOV3.ip tumour xenografts following in vivo cisplatin administration.

\section{MATERIALS AND METHODS}

Chemicals. All chemicals were purchased from Sigma-Aldrich (St Louis, MO, USA), unless otherwise specified. Cisplatin (CDDP) was supplied by Teva Pharmaceuticals Industries Ltd (Petach Tikva, Israel).

Antibodies and reagents. Rabbit anti-HER2 polyclonal antibodies (pAbs) were purchased from Santa Cruz Biotechnology (Santa Cruz, CA, USA); rabbit pAbs raised against bacterial (Bacillus cereus) PtdCho-PLC and selectively cross-reacting with mammalian PtdCho-PLC were obtained and characterised in our laboratory (Podo et al, 1996; Ramoni et al, 2004); goat anti-choline kinase $\alpha$ isoform $(\mathrm{ChoK} \alpha)$ pAbs were purchased from Santa Cruz Biotechnology; mouse monoclonal antibodies (mAb) against $\beta$-actin and glyceraldehyde 3-phosphate dehydrogenase (GAPDH) were from Sigma-Aldrich; FITC-conjugated anti-BrdU mAbs were from Molecular Probes Inc;anti-p21policlonalAbs were from Cell Signalling Technology, Inc; Alexa-Fluor-488-conjugated phalloidin Abs were from Molecular Probes Inc (now part of Invitrogen Corporation, Carlsbad, CA, USA) and mouse anti-nucleoporin Abs from BD Biosciences (Sparks, MA, USA).

Epithelial ovarian cancer (EOC) cells. The human serous EOC cell line of ascitic origin SKOV3 was supplied by American Type Culture Collection (Manassas, VA, USA) and verified for identity by microsatellite analysis at the Fondazione IRCCS Istituto Nazionale dei Tumori, Milano. The SKOV3 cell variant SKOV3.ip was established in our laboratory from the ascitic exudate of female SCID mice as previously described (Yu et al, 1993; Canese et al, 2012), following intraperitoneal (i.p.) injection of SKOV3. Cells were maintained in RPMI supplemented with $10 \%(\mathrm{v} / \mathrm{v})$ fetal calf serum and $2 \mathrm{mmoll}^{-1} \mathrm{~L}$-glutamine and tested for Mycoplasma infection as previously described (Iorio et al, 2010).

In vitro cell treatment with CDDP. SKOV3.ip cells were seeded at a density of $11.5 \times 10^{3}$ cells per $\mathrm{cm}^{2}$, cultured at $37^{\circ} \mathrm{C}$ for $24 \mathrm{~h}$ and then incubated in absence or presence of variable CDDP concentrations in complete medium for different time intervals, as specified. Fresh dilutions of CDDP were made in culture medium immediately before the treatment experiment. Proliferation and cell viability assays were carried out in 96-well microtiter plates or dishes on cells exposed to different CDDP concentrations ranging from $0.1 \mu \mathrm{M}$ to $500 \mu \mathrm{m}$ for 48 and $72 \mathrm{~h}$. Assays were performed on cells exposed for $2 \mathrm{~h}$ to MTT ( $5 \mathrm{mg} \mathrm{ml}^{-1}$ in PBS) as previously described (Paris et al, 2010). For each treatment, determinations were made in six replicates and experiments were repeated six times with independent cell preparations. Cell viability was evaluated by Trypan blue exclusion test.

Western blotting. Protein expression and densitometric analyses were evaluated on total cell lysates ( $20 \mu \mathrm{g}$ of proteins) according to previously described procedures (Spadaro et al, 2008) and/or in the nuclear fraction using the Active Motif Europe kit (Rixensart, Belgium). Beta-actin, GAPDH or nucleoporin were used as quantitative loading controls, as specified. 
Cell cycle and flow cytometry analyses. For cell cycle analyses, bromodeoxyuridine (BrdU, $30 \mu \mathrm{M})$ was added to the medium $1 \mathrm{~h}$ before cell harvest. Flow cytometry analyses were performed using a flow cytometer FACScalibur (BD Biosciences) on cell samples $\left(1 \times 10^{6}\right.$ cells $)$ prepared as previously described and double-stained with FITC-conjugated anti-BrdU mAbs and propidium iodide (PI) (Ramoni et al, 2004; Spadaro et al, 2008).

Confocal laser scanning microscopy (CLSM). Cells, seeded on glass slides, were incubated for different time intervals either in the presence or absence of CDDP, fixed in $4 \%$ formaldehyde for $10 \mathrm{~min}$ at room temperature and then stained with Nile Red $1: 5000$ at $37^{\circ} \mathrm{C}$ for $10 \mathrm{~min}$ followed by Alexa-Fluor-488conjugated phalloidin $(1: 50 \%)$ as previously described (Abalsamo et al, 2012). CLSM observations were performed using a Leica TCS SP2 AOBS apparatus, as previously reported (Spadaro et al, 2008; Paris et al, 2010; Abalsamo et al, 2012).

In vitro enzyme activity assays. Activities of enzymes of the PtdCho cycle were measured at $25^{\circ} \mathrm{C}$ in cell-free systems prepared as previously described and according to ${ }^{1} \mathrm{H}$ NMR protocols developed in our laboratory (Iorio et al, 2005, 2010). In brief, PtdCho-PLC and phospholipase D (PLD) activity rates were determined in total cell lysates using as substrate a short-chain PtdCho, 1,2-dihexanoyl-sn-glycero-3-phosphocholine (C6PtdCho) below the critical micellar concentration and measuring choline production from C6PtdCho hydrolysis in the presence or absence of alkaline phosphatase as described (Iorio et al, 2010). ChoK activity was measured in fresh cytosolic preparations following addition of exogenous choline chloride, ATP and $\mathrm{Mg}^{2+}$ ions (Podo et al, 1996; Iorio et al, 2005).

High-resolution 1H MRS analyses of metabolic profiles in cultured cells. High-resolution ${ }^{1} \mathrm{H}$ MRS experiments $\left(25^{\circ} \mathrm{C}\right)$ were performed at either 400 or $700 \mathrm{MHz}$ using Bruker Avance spectrometers (Karlsruhe, Germany). Quantification of water-soluble metabolites was obtained by NMR analysis of aqueous extracts prepared from cells harvested at $60-70 \%$ confluence $\left(2-30 \times 10^{6}\right.$ cells per sample) as previously described (Iorio et al, 2005). Metabolite concentration was expressed as nmoles referred to the number of extracted cells, using trimethyl-silyl-propionic-2,2,3,3-d4 acid (TSP) sodium salt as chemical shift and peak area reference.

Mobile lipids were detected in intact cells by high-resolution ${ }^{1} \mathrm{H}$ MRS, as previously reported (Iorio et al, 2003; Abalsamo et al, 2012).

Animal model. SKOV3.ip xenografts were obtained in immunodeficient (SCID) mice. Four- to five-week-old female SCID mice were purchased from Harlan, Udine, Italy. All animals were housed and treated in accordance with protocols approved by institutional authorities, in agreement with European Community Directives and with the Italian Law. All efforts were made to minimise animal suffering, to reduce the number of animals used and to adopt alternatives to in vivo testing whenever possible.

SKOV3.ip cells at log phase $\left(2\right.$ or $\left.5 \times 10^{6}\right)$ were suspended in $0.2 \mathrm{ml}$ of either physiological solution or a mixture $(1: 1)$ of growth medium and ice-cold Matrigel (BD Biosciences), and injected into the dorsum of female, 6- to 7-week-old SCID mice (Canese et al, 2012). The greatest longitudinal diameter (length) and the greatest transverse diameter (width) of subcutaneous (s.c.) tumours were measured using a calliper and the tumour volume was calculated according to the formula $V\left(\mathrm{~mm}^{3}\right)=1 / 2$ length $(\mathrm{mm}) \times$ width $^{2}\left(\mathrm{~mm}^{2}\right)$ (Tomayko and Reynolds, 1989). When the tumours reached an average volume of $\sim 58 \mathrm{~mm}^{3}$ (which typically occurred between 8 and 10 days after cell injection) mice $(n=26)$ were randomized into the treatment and the control groups. To deal with homogeneous groups, we excluded those tumours whose volume was larger than $85 \mathrm{~mm}^{3}$ at the beginning of treatment.
Three doses of intravenous (i.v.) CDDP $\left(5 \mathrm{mg} \mathrm{kg}^{-1}\right.$ in $\mathrm{NaCl}$ $150 \mathrm{~mm}$ ) or saline (for the control group) injections were administered to the animals, one dose once per week, for 3 consecutive weeks. The diameters of tumours were measured twice per week during the treatment experiment. The last set of in vivo MR examinations was completed between day 17 and day 18 after start of treatment, before tissue dissection at necropsy.

Immunohistochemistry. Tumour tissues dissected after animal euthanisation were fixed in $4 \%$ formaldehyde, paraffin-embedded, cut into $3-\mu \mathrm{m}$ sections and processed for hematoxylin and eosin (H\&E) or immunohistochemical (IHC) staining. Histological sections were analysed by an experienced anatomy pathologist for tumour tissue morphological appearance with particular attention to the evaluation of necrotic areas. Tumour cell necrosis was evaluated as the percentage of ghost outlines of cells on the histological section. Cytoplasmic clarification, that is, loss of cytoplasmic staining, was quantified as a sign of early necrosis. Haemorrhagic necrosis was evaluated as percentage of tissue in which cell necrosis was associated to a massive red blood cells infiltration. Mitotic activity was evaluated as the number of readily identifiable mitoses counted in 10 slide fields observed at high magnification (high power field, h.p.f., corresponding to $2 \mathrm{~mm}^{2}$ ). $\mathrm{Ki67}$, an indicator of tumour proliferation capacity, and HER2 expression were evaluated by IHC on formalin-fixed, paraffinembedded xenograft sections using a mouse anti-Ki67 mAb (Dako S.p.A, Milan, Italy) and a rabbit polyclonal anti-C-erbB-2 (Dako S.p.A).

In vivo MRI/MRS analyses of SKOV3.ip xenografts. MRI/MRS analyses were conducted at $4.7 \mathrm{~T}$ on a Varian/Agilent Inova horizontal bore system (Agilent, Palo Alto, CA, USA) using a volume coil as transmitter and a surface coil as receiver (RAPID Biomedical, Rimpar, Germany) according to a protocol described in Canese et al (2012). Briefly, animals were anaesthetised with isoflurane $1.5-2.0 \%$ in $\mathrm{O}_{2} 11 \mathrm{~min}^{-1}$. Anatomical (T1-weighted, T2-weighted and proton density) and diffusion-weighted MRI were acquired according to a protocol described in (Canese et al, 2012). The apparent diffusion coefficient and vascular signal fraction (VSF) parameters were derived as described in Sala et al (2010). ADC of regions that showed a typical tumour appearance in terms of hyperintensity in T2W and in DW images were selected from ADC map. We defined these region as viable or lowdiffusivity areas (see also the Discussion). Quantitative MRS (PRESS TR/TE $=4000 / 23 \mathrm{~ms}$ ), which included in vivo water T2 and ex vivo water content measurements, were performed. LCModel was used for the spectral fitting (Provencher, 1993).

After s.c. cell implantation, animals were monitored weekly by MR examinations starting from early tumour detection until animal sacrifice. At necropsy, tumour tissues were removed, immediately frozen in liquid nitrogen and stored for 2-5 months before analyses.

Ex vivo and in vitro ${ }^{1} \mathrm{H}$ MRS analyses of metabolites in tumour specimens. High-resolution ${ }^{1} \mathrm{H}$ MRS analyses were performed on intact EOC xenograft specimens using a high-resolution Magic Angle Spinning (HR MAS) technique on a Bruker Avance spectrometer at $9.4 \mathrm{~T}$ (Karlsruhe, Germany) as described in our previous study (Canese et al, 2012).

Statistical analyses. Data were analysed using GraphPad Software version 3.03. Statistical significance of differences was determined by two-ways or one-way ANOVA, Student's $t$-test or by equality of variance $F$-test as specified. Differences were considered significant at $P<0.05$. 


\section{RESULTS}

${ }^{1} \mathrm{H}$ MRS choline profile of SKOV3 and SKOV3.ip cells. In vivo passage of the HER2-overexpressing SKOV3 cells in the peritoneum of SCID mice allowed us to isolate a SKOV3 cell variant, SKOV3.ip, characterised by a $1.7 \pm 0.2$ ( \pm s.d.) fold increase in the overall HER2 expression $(P \leqslant 0.001)$ compared with the parental cell line (e.g., in Figure 1A, inset). Following subsequent in vitro passage(s) and re-injection in the peritoneum of SCID mice, SKOV3.ip cells induced formation of ascites in only $15 \pm 2$ days, compared with the $60 \pm 7$ days needed by the parental SKOV3.ip cells to produce a similar amount of ascitic exudates (Figure 1A). Although this result showed that SKOV3.ip cells possessed a much higher level of in vivo tumorigenicity compared with SKOV3, the in vitro proliferation of the two cell lines was not significantly different (Figure 1B).

High-resolution ${ }^{1} \mathrm{H}$ NMR analysis of aqueous extracts of cells harvested at early confluence showed an average 1.7 -fold elevation $(P<0.002)$ in the PCho content of SKOV3.ip compared with SKOV3, as shown in Figures $1 \mathrm{C}$ and D and Table 1. The full spectra of cell extracts (examples in Supplementary Figure 1A) showed that the increase in PCho content under the 'total choline' resonance centred at 3.2 p.p.m. $(\mathrm{tCho}=[\mathrm{PCho}+\mathrm{GPCho}+$ free choline(Cho)]) was the main metabolic change detected by MRS between the two cell lines. No statistically significant differences were in fact found in the levels of the other MRS-detectable metabolites, including GPCho and Cho (Figure 1D and Supplementary Figure 1). These results showed a 1.6-fold increase in the tCho pool in SKOV3 compared with SKOV3.ip cells (Table 1). Enzymatic assays showed a significant 2.9-fold increase in the activity of PtdCho-PLC in SKOV3.ip compared with SKOV3 cells $(P<0.05)$, a borderline significant 1.8 -fold increase in that of ChoK $(P<0.07)$ and unaltered activity levels for PtdCho-PLD (Table 1).
Cytostatic effect of CDDP on in vitro cultured SKOV3.ip cells. The SKOV3.ip sensitivity to CDDP was first evaluated by MTT assay in the presence of increasing concentrations of the drug from 0.1 to $500 \mu \mathrm{M}$ for $48 \mathrm{~h}$ (Figure $2 \mathrm{~A}$ ). Similar results were obtained at $72 \mathrm{~h}$ of SKOV3.ip cell exposure to the drug (data not shown). No significant differences were detected in the sensitivity to the drug of the SKOV3 and SKOV3.ip cell lines (data not shown). For the subsequent experiments, we utilised the CDDP concentration of $5 \mu \mathrm{M}$, which inhibited SKOV3.ip cell proliferation by $45.0 \pm 0.3 \%$ at $48 \mathrm{~h}$ (Figure $2 \mathrm{~A}$ ) and by $50.7 \pm 0.3 \%$ at $72 \mathrm{~h}$ of cell exposure $(P$ (treated $v s$ untreated $) \leqslant 0.001, n=21)$, without inducing any significant alteration in cell viability $(>90 \%$ at any tested time of exposure to the drug).

Figure 2B shows the time course of cell count in SKOV3.ip cell cultures exposed to $5 \mu \mathrm{M}$ CDDP, compared with untreated control samples.

Flow cytometry analyses showed that at this dose CDDP induced cell cycle arrest at the $G_{0} / G_{1}$ phase (Figures $2 \mathrm{C}$ and $\mathrm{D}$ ), whose cell fraction increased from $\sim 50 \%$ to $80 \%$ at both $48 \mathrm{~h}$ and $72 \mathrm{~h}$, whereas the S phase fraction decreased from over $30 \%$ to less than $10 \%$. The $G_{2} / M$ phase fraction was practically the same in CDDP-treated cells at $48 \mathrm{~h}$ and $72 \mathrm{~h}$. No hypodiploid DNA peak could be detected in CDDP-treated cells.

The observed cell cycle arrest and the consequent block of cell proliferation were consistent with an over two-fold increase in p21 in CDDP-treated cells, in which this protein exhibited a mainly nuclear localisation (Figure 2E).

Under the adopted experimental conditions, CDDP also induced substantial changes in cell morphology, with a two-fold increase in the average cell volume compared with untreated controls (representative examples in Figure 3A).

These changes were associated with an accumulation of intracellular Nile-Red-stained lipid bodies, in the presence of unaltered nuclear morphology. ${ }^{1} \mathrm{H}$ MRS analyses of intact cells showed about two-fold increases in the areas of mobile lipid (ML)
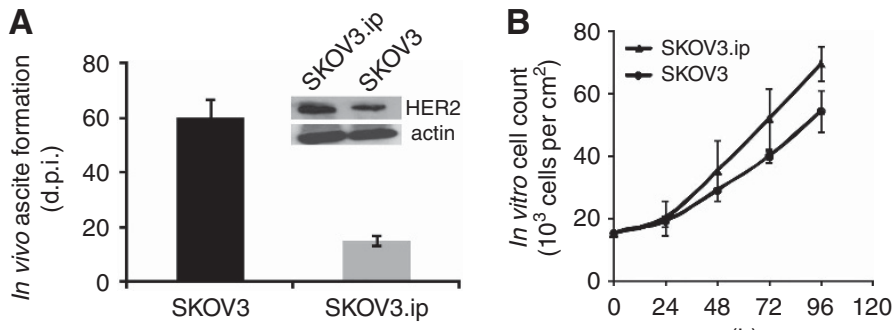

(h)
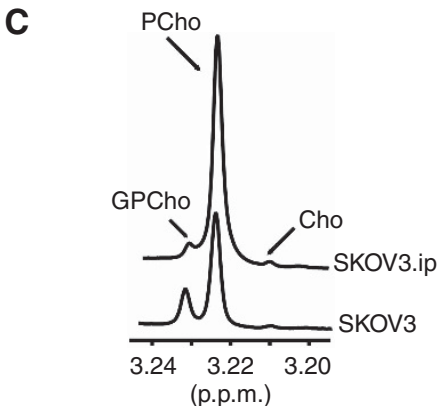

D

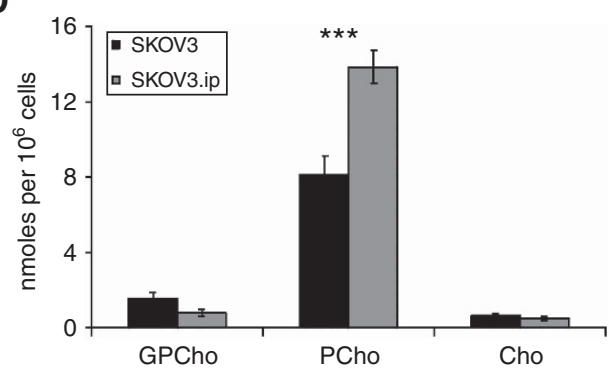

Figure 1. In vivo ascites' formation, cell proliferation and 1H MRS tCho profile of human SKOV3 and SKOV3.ip ovarian cancer cells. (A) Mean time (days post implant, d.p.i.) of ascites' formation following injection of SKOV3 or SKOV3.ip cells in the peritoneal cavity of female SCID mice ( $n=3$ independent experiments). Insert: representative example of western blotting of HER2 in total cell lysates. (B) Cell proliferation of in vitro cultured cells ( $n=4$ independent experiments; no statistically significant difference at any time). (C) Representative examples of partial ${ }^{1} \mathrm{H}$ NMR spectra (9.4 T) of aqueous extracts of cells harvested at early confluence. Peak assignment: Cho, free choline; GPCho, glycerophosphocholine; PCho, phosphocholine. (D) Quantification of GPCho, PCho and Cho (nmoles per $10^{6}$ cells) in cell extracts. Data represent mean values \pm s.e.m. for SKOV3 $(n=13)$ and SKOV3.ip cells $(n=37) .{ }^{\star \star *} P \leqslant 0.002$. 
signals arising from either saturated or unsaturated segments of neutral lipid acyl chains, mainly attributed to triacylglycerols in the formed cytoplasmic lipid bodies (Iorio et al, 2003).

Table 1. Choline metabolites and enzyme activity rates in the human ovarian carcinoma cell line SKOV3 and its in vivo passaged cell variant SKOV3.ip

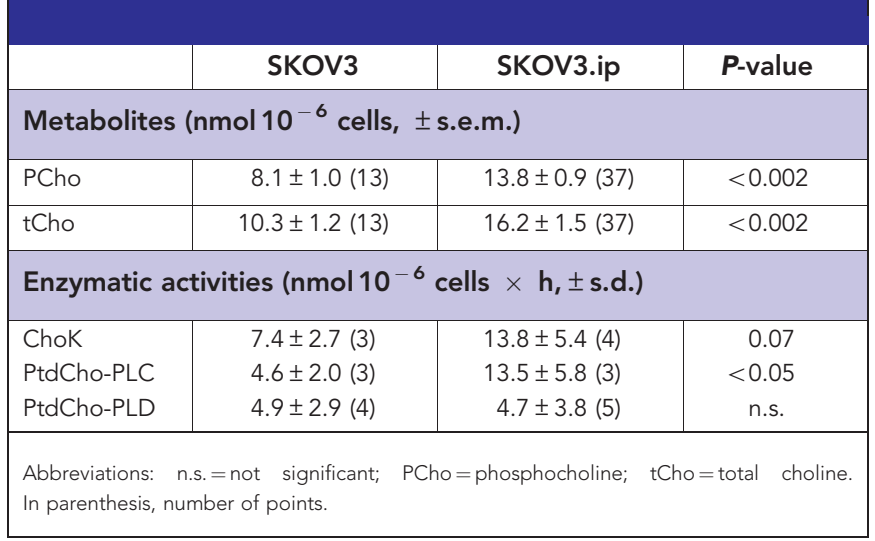

A

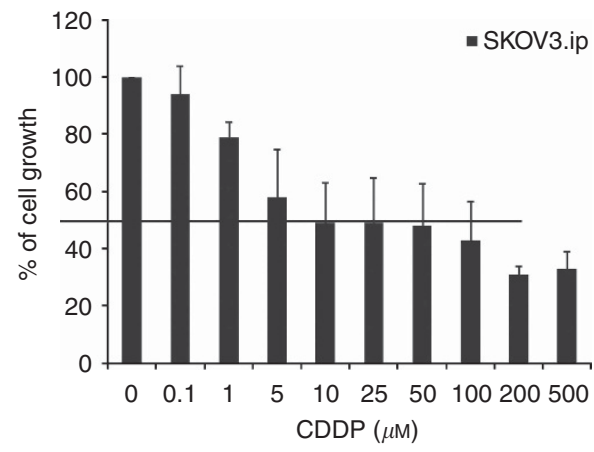

C

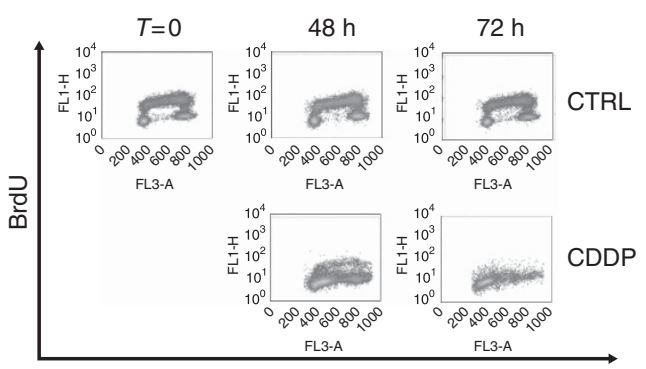

$\mathrm{Pl}$

E

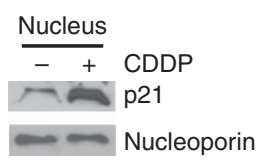

Interestingly, the remarkable molecular and biological alterations induced by CDDP on in vitro SKOV3.ip cell proliferation and cell morphology were not associated with any significant change in the levels of choline-containing metabolites (Figure 3C), nor in the activities of ChoK, PtdCho-PLC and PLD (Figure 3D).

Effects of CDDP on in vivo growth and MR parameters of SKOV3.ip xenografts. A reduction in the in vivo tumour growth was detected in CDDP-treated compared with saline-treated SKOV3.ip xenografts (Figure 4A). The tumour weights were analysed with a two-ways ANOVA, with treatment (SAL, CDDP) $\times$ time $(6$ points) design. In the post-treatment tumours, ANOVA revealed an effect of treatment, $F(1,24)=4.310, P<0.05$, and an effect of treatment by time interaction, $F(4,96)=9.209, P<0.0001$. Bonferroni post-hoc analyses at each time point showed that the difference in tumour weight (as well as in the percentage of tumour growth) between treated and controls became significant after the third dose (Figure 4A).

T1-weighted, T2-weighted and proton density MR images showed differences in the tumour composition of the two groups of xenografts, as shown in the examples reported in Figure 4B. In particular, there was a clear reduction of the areas of macroscopic necrosis, detected as a decrease in the extension of hyperintense
B

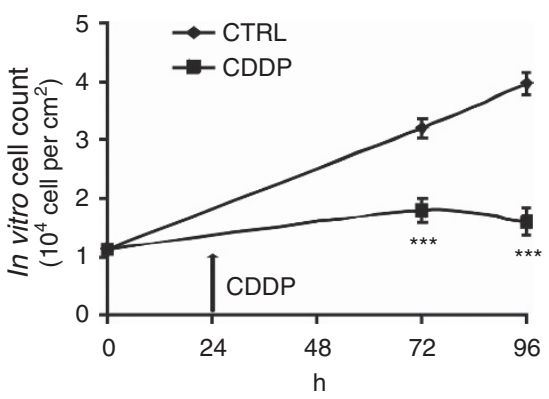

D

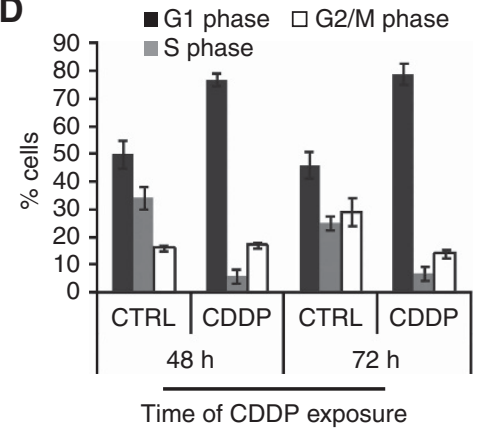

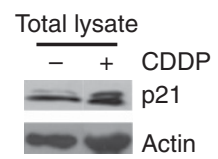

Figure 2. Cytostatic effects of cisplatin (CDDP) on in vitro cultured SKOV3.ip cells. (A) Inhibition of cell proliferation induced by CDDP $(0.1-500 \mu \mathrm{M})$ on cells exposed for $48 \mathrm{~h}$ to the drug (see Materials and Methods). Cell counts were quantified as percentages of the number of cells in untreated controls at $t=0$. The histogram values represent the mean ( \pm s.d.) of six independent series of assays. (B) Cell proliferation of SKOV3.ip cells exposed to $5 \mu \mathrm{M}$ CDDP for 48 and $72 \mathrm{~h}$, compared with untreated controls, CTRL (mean values \pm s.d., $n=21,{ }^{\star}$, $P<0.001$. (C) Bivariate histograms showing DNA content ( $x$ axis, propidium iodide, Pl) and bromodeoxyuridine incorporation ( $y$ axis, BrdU, fluorescein isothiocyanate fluorescence) in SKOV3.ip cells after 48 and $72 \mathrm{~h}$ of cell exposure to CDDP, compared with untreated controls. (D) Changes in the cell cycle fractions Go/G1, S and G2/M in CDDP-treated cell cultures, compared with untreated controls (mean values \pm s.d. of $n=3$ independent experiments). (E) Representative western blotting of p21 in total cell lysate and nuclear fraction of SKOV3.ip cells either untreated or exposed to CDDP at $48 \mathrm{~h}$ ( $n=2$ independent experiments). Beta-actin and nucleoporin were used as loading controls for the cell lysate and nuclear fraction preparations, respectively. 

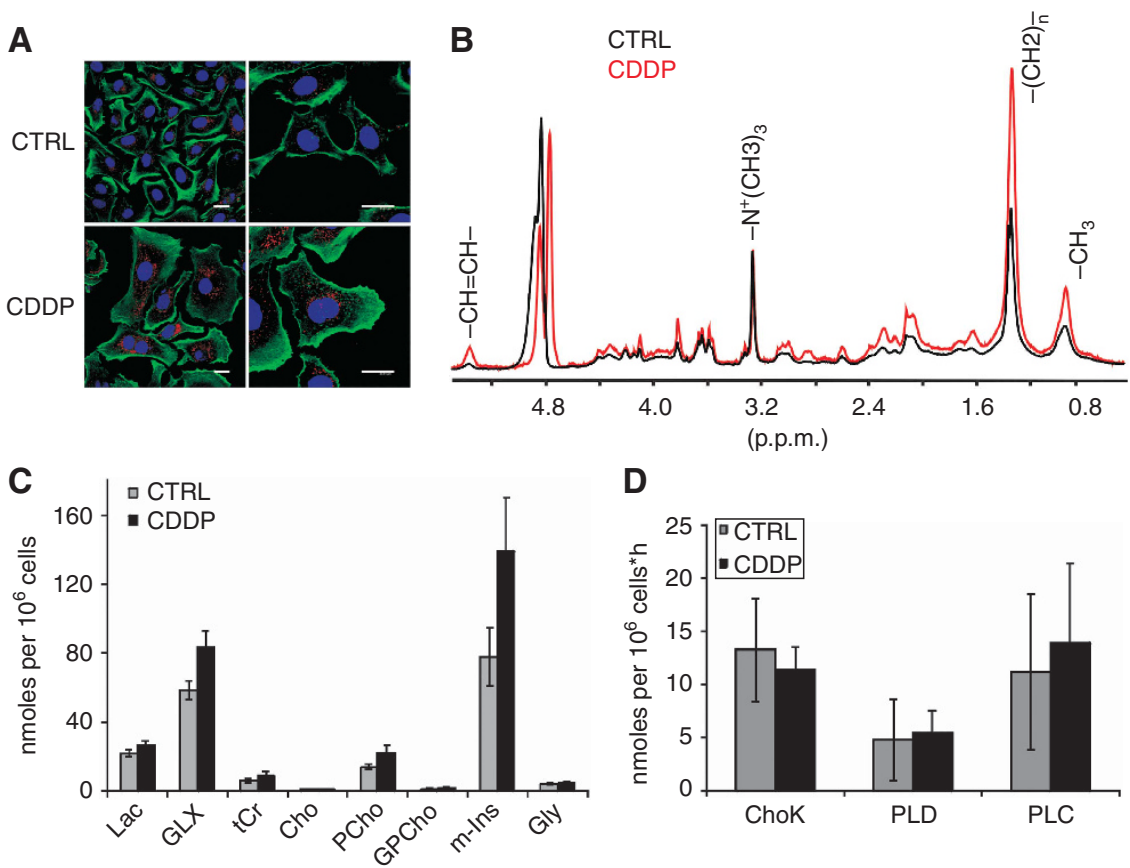

D

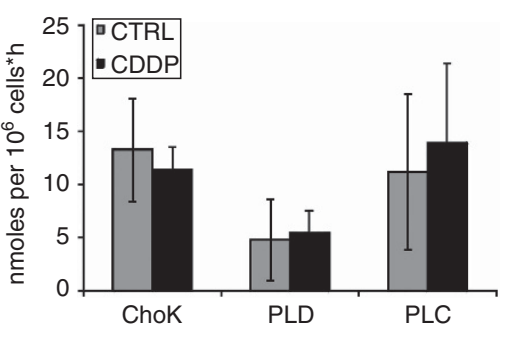

Figure 3. Morphological and metabolic changes induced by CDDP on in vitro cultured SKOV3.ip cells. (A) CLSM analyses of cells cultured for $48 \mathrm{~h}$ in the presence of $5 \mu \mathrm{M}$ CDDP and untreated controls (CTRL), fixed and double-stained with Nile Red (detected in red) and phalloidin 488 (detected in green). Nuclei were stained with DAPI (detected in blue). Scale bars, $23.8 \mu \mathrm{m}$. The reported images are representative examples of three independent experiments. (B) Examples of ${ }^{1} \mathrm{H}$ NMR spectra of intact SKOV3.ip cells exposed to $5 \mu \mathrm{M}$ CDDP for $48 \mathrm{~h}$ (red spectrum) compared with the relative untreated control (black spectrum). Peak assignments: ML resonances detected in the spectrum: methine protons at 5.2 p.p.m. $(-\mathrm{CH}=\mathrm{CH}-)$; fatty chain methylene group at 1.3 p.p.m. $\left(-\left(\mathrm{CH}_{2}\right)_{n}\right)$ - and methyl group at 0.9 p.p.m. $\left(-\mathrm{CH}_{3}\right)$. The total choline-containing metabolites at 3.2 p.p.m. $\left(-\mathrm{N}+\left(\mathrm{CH}_{3}\right)_{3}\right)$. (C) Quantification of choline-containing metabolites in aqueous extracts of CDDP-treated SKOV3.ip cells (CDDP, $5 \mu$ M, 48-72 h) compared with untreated controls. Data represent mean values \pm s.e.m. (CTRL, $n=16 ; C D D P, n=12 ; P \geqslant 0.05$ for all metabolites. Abbreviations: Cho = free choline; Glx=glutamate plus glutamine; Gly=glycine; GPCho=glycerophosphocholine; Lac =lactate; $\mathrm{m}$-Ins = myo-inositol; $\mathrm{PCho}=$ phosphocholine; $\mathrm{tCr}=$ total creatine (creatine plus phosphocreatine). (D) Activityrates of choline kinase (ChoK) and PtdCho-phospholipases (phospholipase D, PLD, and phospholipase C, PLC) in untreated (CTRL) and cisplatin (CDDP)-treated cells.

regions in the T2-weighted images of CDDP compared with the SAL-treated tumours.

For those tumours which were dissected at the end of longitudinal in vivo MRI analyses, histological evaluations showed CDDP-induced morphological effects fully compatible with those detected by non-invasive MR imaging (Supplementary Figure 2). MRI images indicated that necrotic areas were more evident in saline-treated (upper panels) than in CDDP-treated tumours (lower panels). This effect was likely due to the fact that the faster tumour growth in control animals was associated with increased hypoxia and consequent formation of necrosis in central areas of tumour lesions. No significant differences were instead observed in the expression of HER2 and Ki67 (excluding some alteration only evident at the tumour periphery) nor in the average mitotic index in the viable part of the tumours.

The ADC maps (Figure 4B) allowed quantification of the mean $\mathrm{ADC}$ value, a parameter related to tissue cellularity and water compartmentalisation. A significant reduction of the ADC mean value was detected at early stages (24-48 h after the first dose) in the viable part of CDDP-treated tumours compared with the control ones (one-way ANOVA: $F(3,15)=6.195, \quad P<0.01$ ) (Figure 5A). These regions have been selected on the basis of their hyperintensity in $\mathrm{T} 2 \mathrm{~W}$ and in DW images and correspond to regions of low diffusivity. They showed an average ADC of $6.6 \pm 0.5 \mathrm{~mm}^{2} \mathrm{~s}^{-1}$ (ranging between 7.3 and $6.2 \mathrm{~mm}^{2} \mathrm{~s}^{-1}$ ) before the beginning of the treatment. Although smaller, a decrease in the mean ADC value was persistent up to $24-48 \mathrm{~h}$ after the third treatment. This result was in agreement with the cell swelling of CDDP-treated SKOV3.ip cells detected by optical microscopy examinations of in vitro cultured SKOV3.ip cells (Figure 3A).
No differences were instead detected in the VSF values, a parameter related to vascularisation/perfusion of the tumours (Figure 5B).

Substantial differences were also detected in the distribution of $\mathrm{ADC}$ values in the entire set of CDDP-treated tumours compared with those examined before treatment (Figure 5C), confirming the reduction of macroscopic necrotic areas in these tumours (visible as a reduction in the tumour component possessing high ADC values). A much smaller effect was instead detected in the salinetreated control tumours (Figure 5D).

A quantitative protocol including measurements of water T2 and content values allowed determination of the absolute levels of choline-containing compounds (tCho) and another well-represented metabolite, myo-inosytol (m-Ins). The water content was found to be $81.4 \pm 1.1 \%(n=6)$ and $79.7 \pm 2.3 \%(n=5)$ in CDDPand in SAL-treated tumours, respectively, suggesting that no changes occurred in this parameter following the second and third CDDP treatments $(P=0.13)$. Using these values of water content, no significant differences were detected in the absolute quantification of in vivo ${ }^{1} \mathrm{H}$ MRS profiles of CDDP-treated compared with control SAL-treated tumours, as shown in Figures 6A and B. The results obtained for the tCho pool and $\mathrm{m}$-Ins are summarised in Table 2. The concentration levels of these metabolites were analysed with a two-ways ANOVA, with treatment (CDDP, SAL) $\times$ time (2 points) design. No effects due to CDDP treatment nor interactions (time $\times$ treatment) were found neither in the pre- nor in the post-treatment group for tCho and m-Ins concentration values.

The ex vivo HR MAS MRS analyses of intact tumour samples confirmed that in vivo CDDP treatment of SKOV3.ip xenografts 

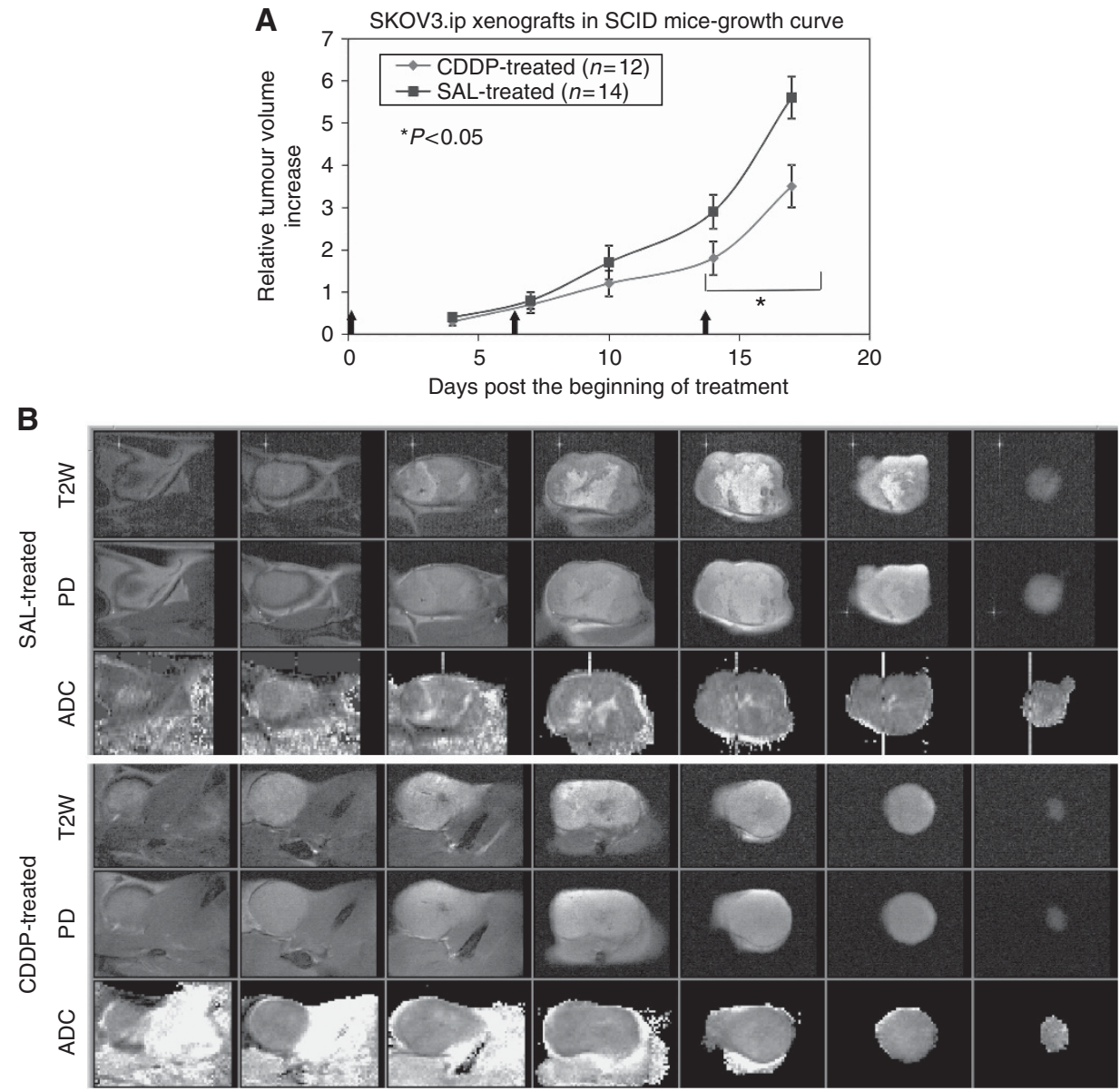

Figure 4. Effects of CDDP on in vivo growth and MRI of SKOV3.ip xenografts in SCID mice. (A) Tumour growth of xenografts and effects of three consecutive administrations of CDDP (arrows, $5 \mathrm{mg} \mathrm{kg}^{-1}$ per dose) on tumour volume. ${ }^{*} P<0.05$, volume of treated vs control tumours. (B) Multislice coronal MRI-detected images and ADC maps acquired in vivo from CDDP- and saline (SAL)-treated xenografts at 29 days post implantation, 4 days after the third treatment.

(Figure 6C) did not exert any significant effect on the in vivo MRSdetectable profiles of aqueous metabolites, in spite of the cytostatic effect of the drug and the clear-cut changes detected at very early stages of treatment at the level of the ADC mean values and distribution in this tumour model.

\section{DISCUSSION}

EOC and other malignancies with poor prognosis may overexpress HER2, a member of the EGF receptors' family. HER2 overexpression has been associated with a poor drug response in human ovarian cancer and a close relationship has been reported between HER2 and CDDP response in ovarian cancer cells (Lafky et al, 2008; Ohta et al, 2012; Cheng et al, 2013). The balance between cytostatic $v s$ cytotoxic effects induced by CDDP in cancer cells is a consequence of DNA damage produced by CDDP-DNA adducts, which is in turn modulated by the interplay between tumour suppressors and oncogenic signalling controlling DNA synthesis, suppression of RNA transcription and effects on cell cycle, cell survival and death (Wang and Lippard, 2005).

Non-invasive monitoring of the effects of a CDDP-based anticancer treatment on a HER2-overexpressing ovarian cancer model may therefore provide relevant information to test and improve the effectiveness of a newly designed combination of conventional and targeted therapies and refine a possible tailored adjustment of personalised treatment strategies. We here focused attention on choline metabolism of two HER2-overexpressing EOC cell lines possessing different in vivo growth capability in SCID mice, SKOV3 and its SKOV3.ip cell variant. The latter was isolated from ascites developed in SCID mice following i.p. injection of SKOV3 cells and was then maintained as a stable cell line in vitro. Compared with SKOV3, SKOV3.ip cells exhibited higher HER2 protein overexpression and enhanced in vivo tumorigenicity, as detected by faster in vivo tumour growth and reduced animal survival, when injected in SCID mice. We then used SKOV3.ip cells, as a model to evaluate MR-detectable spectral and physiological effects induced in vivo by CDDP, a conventional drug currently used in clinical oncology.

Significant increases in intracellular PCho and tCho levels measured in SKOV3.ip compared with SKOV3 cells were associated with practically identical curves of in vitro cell growth of the two cell lines up to at least $72 \mathrm{~h}$, arguing against a role of the PCho content as a direct indicator of cancer cell proliferation.

The increase in PCho detected in SKOV3.ip cells is in substantial agreement with the reported increases of this metabolite in HER2-transfected breast cancer cells (Aboagye and Bhujwalla, 1999) and in oncogene-transformed cells of different types (Bhakoo et al, 1996; Ronen et al, 2001; Podo et al, 2011). Our previous studies (Iorio et al, 2005, 2010) showed that elevated PCho contents in EOC cells were associated with the activation of two enzymes responsible for PCho production in the PtdCho cycle, ChoK and PtdCho-PLC. In the present study, we found that a 1.7 -fold increase in PCho $(P<0.002)$ in the in vivo passaged SKOV3.ip compared with the parental SKOV3 cells was associated 

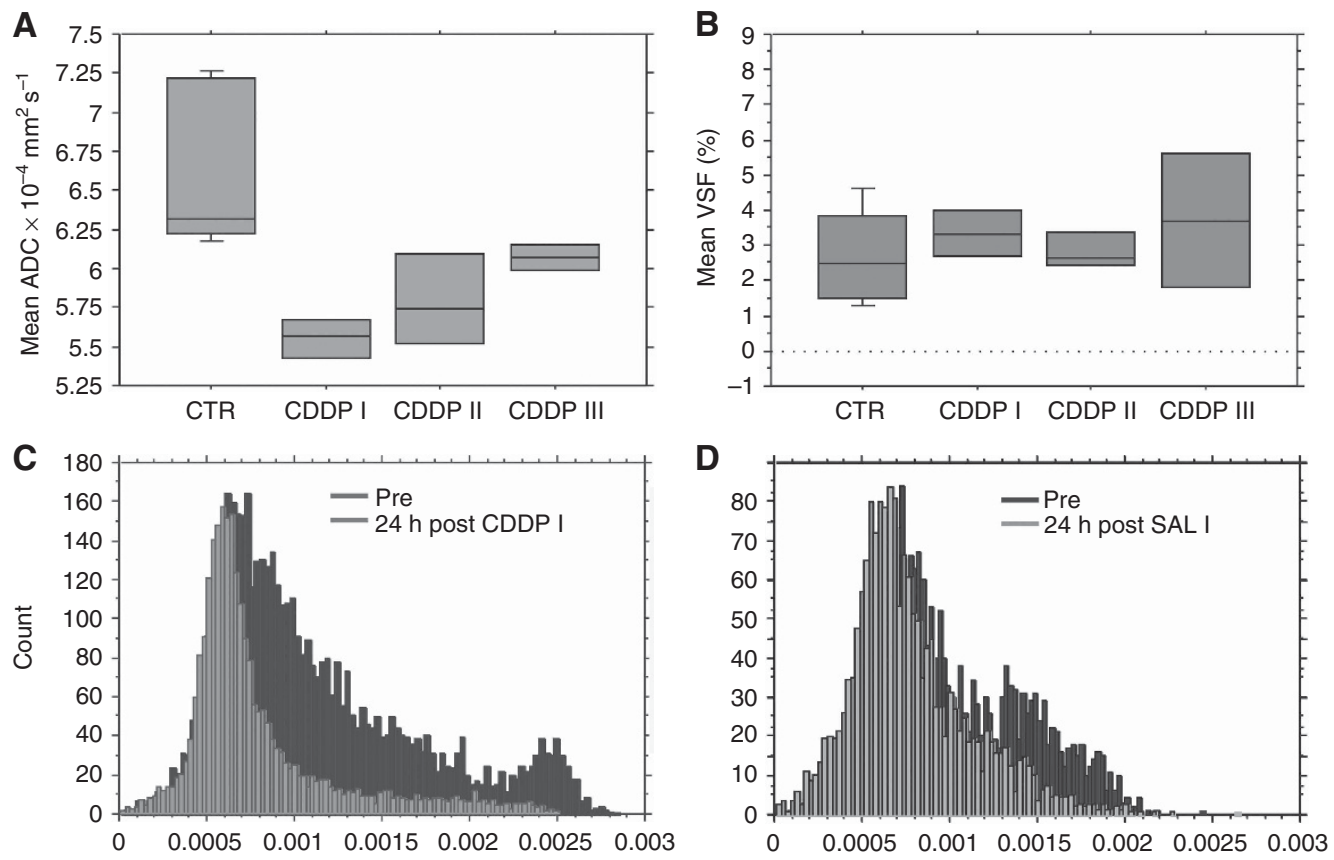

Figure 5. Changes of in vivo DW-MRI parameters in SKOV3.ip xenografts following treatment with CDDP. (A and B) Mean values of ADC and VSF measured in the viable tumour regions (i.e., excluding hyperintense regions in T2-weighted and DW images, corresponding to areas of macroscopic necrosis (see arrows in Figure 4B) before and $24-48 \mathrm{~h}$ after each of the three CDDP treatments. (C and D) Changes in ADC distributions in an in vivo xenograft before and after the first CDDP treatment (normalised to the pre-treatment value). A marked reduction in the percentage of the tumour exhibiting high ADC values was observed for the CDDP-treated group.
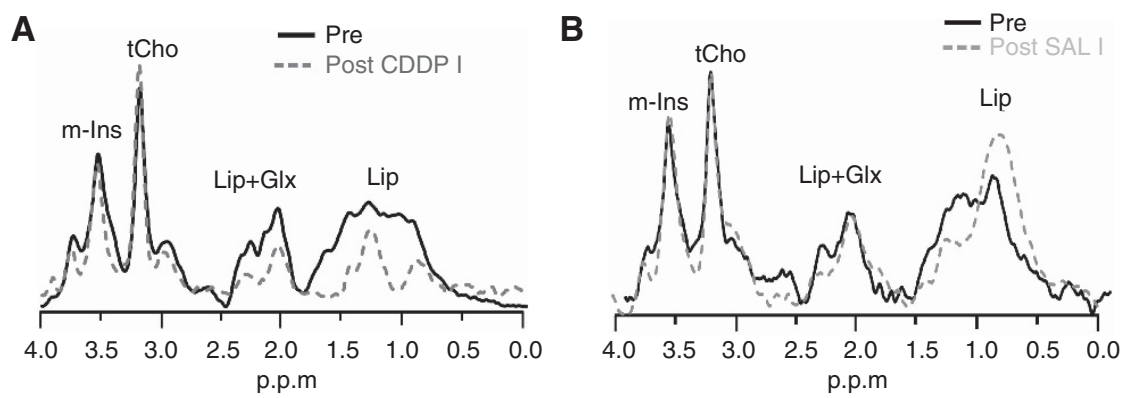

Ex vivo HR-MAS relative analyses

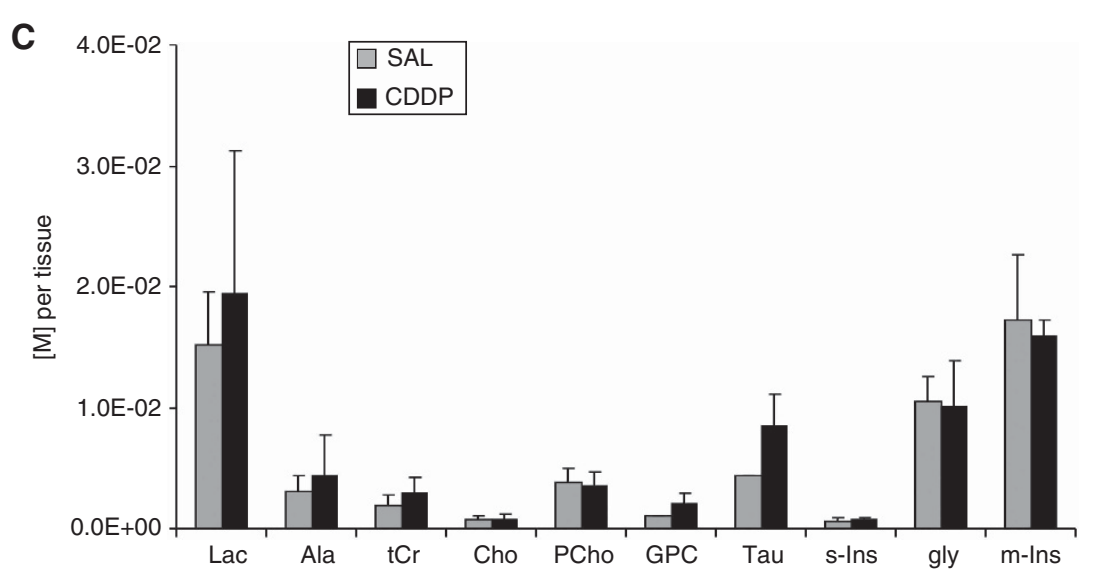

Figure 6. In vivo ${ }^{1} \mathrm{H}$ MRS profiles of CDDP-treated SKOV3.ip xenografts. (A, B) Typical spectra of xenografts obtained before and after CDDP- or SAL treatment. Peak assignment: $\mathrm{m}$-Ins, myo-inositol; tCho, choline-containing compounds; Lip, lipids; Glx, glutamine plus glutamate.

(C) Quantitative metabolite determinations performed by ex vivo HR MAS ${ }^{1} \mathrm{H}$ MRS in intact specimens dissected from xenografts at 15-18 d.p.i. ( $S A L, n=2 ; C D D P, n=6$ ). The relative content of each metabolite ([M] per mg tissue) was determined from the integral (in arbitrary units) of the selected chemical group for the indicated metabolite $(M)$, normalised to the number of protons of the chemical group. Error bars $= \pm \mathrm{s}$.d. for $n \geqslant 3$. Abbreviations: Ala = alanine; Cho=free choline; Gly=glycine; GPCho=glycerophosphocholine; Lac=lactate; $m$-Ins = myo-inositol; $\mathrm{PCho}=$ phosphocholine; s-Ins = scyllo-inositol; $\mathrm{Tau}=$ taurine; $\mathrm{tCr}=$ total creatine (creatine plus phosphocreatine). 


\begin{tabular}{|c|c|c|c|c|}
\hline & \multicolumn{2}{|c|}{ tCho (mM) } & \multicolumn{2}{|c|}{ m-Ins (mM) } \\
\hline & $\begin{array}{l}\text { CDDP- } \\
\text { treated } \\
(n=4)\end{array}$ & $\begin{array}{c}\text { SAL- } \\
\text { treated } \\
(n=4)\end{array}$ & $\begin{array}{l}\text { CDDP- } \\
\text { treated } \\
(n=4)\end{array}$ & $\begin{array}{c}\text { SAL- } \\
\text { treated } \\
(n=4)\end{array}$ \\
\hline Pre-treatment & $3.2 \pm 0.9$ & $3.1 \pm 0.9$ & $10.4 \pm 3.9$ & $9.8 \pm 2.8$ \\
\hline $\begin{array}{l}\text { 24-48 } \mathrm{h} \text { after } \\
\text { 1st treatment }\end{array}$ & $3.8 \pm 0.8$ & $3.8 \pm 0.9$ & $11.6 \pm 2.9$ & $13.3 \pm 1.3$ \\
\hline $\begin{array}{l}\text { 24-48 } \mathrm{h} \text { after } \\
\text { 2nd treatment }\end{array}$ & $4.1 \pm 0.6$ & $4.4 \pm 0.6$ & $12.5 \pm 2.0$ & $15.0 \pm 3.4$ \\
\hline
\end{tabular}

with a significant about three-fold increase in the mean activity of PtdCho-PLC and an only borderline significant 1.8 -fold increase in ChoK activity (Table 1 ).

At the dose of $5 \mu \mathrm{M}$, CDDP caused in SKOV3.ip cells an $\sim 50 \%$ decrease in cell proliferation, associated with $\mathrm{G}_{0} / \mathrm{G}_{1}$ cycle arrest (in absence of apoptosis, as indicated by the lack of sub-Go DNA peak(s)), cell swelling and an about two-fold increase in p21. The induction of p21, an inhibitor of cyclin-dependent kinase complexes, was in agreement with the inhibition of cell cycle progression and block in the G1 phase of CDDP-treated cells (Sperka et al, 2012).

Changes in the tCho profile were reported in apoptotic glioma and osteosarcoma cells after exposure to CDDP (Duarte et al, 2010; Mirbahai et al, 2011). However, in our experimental conditions, CDDP did not induce apoptosis nor necrosis, likely because SKOV3 cells carry a complex set of genomic alterations, which include HER2/neu amplification, mutation of PI3KCA and p53 null. Under these conditions, no changes were induced by CDDP on the PCho level, nor on the activities of PtdCho-PLC, ChoK or PLD. An interesting spectral modification was instead the appearance in the ${ }^{1} \mathrm{H}$ NMR spectra of intact CDDP-treated SKOV3.ip cells of signals typical of ML accumulation, suggesting that an altered ML profile could provide a useful indicator of EOC cell response to the stress induced by the cytostatic (but not cytotoxic nor apoptotic) action of this drug (Delikatny et al, 2011). The role of ML after anticancer treatment was pioneered by Blankenberg et al (1996), who demonstrated increased levels of these signals in the course of drug-induced apoptosis of several carcinoma cell lines. Notably, CDDP has also been reported to induce activation of pathways linked to ML metabolism in growtharrested cells and in cells induced to death (Mirbahai et al, 2011; Mirbahai et al, 2012; Pan et al, 2013). Activation of phospholipase $\mathrm{A}_{2}$ isoforms or an unpaired mitochondrial function are held as major causes likely responsible for the appearance of ${ }^{1} \mathrm{H}$-MRSvisible lipids and lipid droplet formation in cancer cells exposed to drugs or to other inducers of cellular stress (Hakumaki et al, 1999; Delikatny et al, 2002; Iorio et al, 2003).

This body of evidence showed that, with the exception of increased signals arising from mobile lipids, no significant changes could be detected in the levels of other ${ }^{1} \mathrm{H}$ MRS-detectable metabolites (including PCho) in our CDDP-treated cancer cells, in spite of the well-evident cytostatic effects exerted by the drug. In other words, drug-induced cytostatic effects do not necessarily lead to changes in PCho (or tCho profile) levels in cancer cells. This warning could be of general interest for a series of studies currently devoted to assess the effectiveness of newly designed targeted therapies, whose effects can be mainly cytostatic rather than cytotoxic (Garrett and Workman, 1999). Changes in the tCho profile can however also occur in cancer cells exposed to cytostatic agents. For instance, we previously showed that specific inhibition of PtdCho-PLC by tricyclodecan-9-xanthogenate (D609) at a dose which caused in EOC cells an arrest of cell proliferation similar to that induced by serum deprivation (in absence of cell cytotoxicity) resulting in a $30-50 \%$ decrease in PCho at $24 \mathrm{~h}$ (Iorio et al, 2010). Similarly, simultaneous decreases in the PCho level and in cell proliferation were reported, in absence of apoptosis, in breast cancer cells under conditions of RNA interference-mediated ChoK suppression (Glunde et al, 2005). This body of evidence, together with the results of the present study, suggests the conclusion that changes in the tCho profile of cancer cells treated with a cytostatic agent can be expected in cases of specific targeting of PtdCho-cycle enzymes (such as ChoK and PtdCho-PLC), but could not be taken as a general consequence of cell proliferation arrest.

Quantitative analysis of the tCho peak in the in vivo MR spectra of SKOV3.ip xenografts failed to detect any drug-induced changes, as expected from the results obtained on in vitro CDDP-treated SKOV3.ip cells. A similar conclusion was obtained from quantitative analysis of $\mathrm{m}$-Ins, a different metabolite apparently not involved in the cytostatic action of this drug. Unfortunately, the well-known difficulties in quantifying lipid signals in body regions other than brain, mainly linked to signal contamination from surrounding tissues, prevented the use of ML signals as spectroscopic indicators of the response to SKOV3.ip xenografts to CDDP.

Anatomical MRI (T1W and T2W) allowed the detection of decreases in macroscopic necrotic regions in implanted SKOV3.ip xenografts, although it remains difficult to establish whether this reduction could be caused by the treatment itself, rather than by a restriction in the size of treated tumours. For this reason, a functional evaluation of tissue properties was performed using DWI approaches, to assess whether an early prediction of SKOV3.ip tumour response to CDDP therapy could be obtained on this basis. A previous work performed by our group showed the capability of DWI to detect ovarian masses within the peritoneum of SCID mice (Canese et al, 2012) and early therapy response to an anti-angiogenic treatment in ovarian cancer models derived from patients (Nardo et al, 2011).

Only a few clinical studies measured ADC in pelvic diseases because of the difficulties encountered in body DWI due to movement artifact. These studies showed that DWI may be the most appropriate imaging modality for monitoring the response to neoadjuvant platinum-based chemotherapy in patients with advanced ovarian cancer. In fact, Sala et al (2012) found significant differences in baseline ADC values among primary ovarian cancer, omental cake, and peritoneal deposits, indicating that diffusivity profiles may be tumour-site dependent. Moreover, ADC of responders to platinumbased therapy was found to be higher than that of non-responders, showing a predictive value for the use of DWI approaches.

Kyriazi et al (2011) showed that ADC histogram parameters have predictive value in monitoring the chemotherapy response (assessed using integrated morphologic and biochemical criteria), which was associated with an early and sustained increase in ADCs. Lack of response was associated with stability of all histogram parameters. In the study by Kyriazi, the parameter with the highest accuracy in identifying responders was the per cent change of the 25th percentile suggesting that, within a tumour, the domains of lower diffusivity may be more sensitive to cytotoxic mechanisms. In fact, the wellestablished inverse correlation between ADC and cell density implies that, in heterogeneous cancer lesions, regions of lower ADC value are the most representative of the tumour grade and biological behaviour, because of their increased cellular concentration (Yamashita et al, 2009). The domains characterised by a lower diffusivity are also those corresponding to the viable part of the tumour, because in the regions with higher ADC values the increase in the extracellular space can be due to microscopic or macroscopic areas of necrosis, possibly due to hypoxia or to destruction of cellular 
membranes following anticancer drug treatment (Koh and Collins, 2007). For this reason, we concentrated our analysis on the lower diffusivity domains.

Basing on the $b$-value used in the present work, we were exploring the effect of the CDDP treatment on the extracellular space of the SKOV3.ip xenografts. We observed a marked ADC reduction at $24-48 \mathrm{~h}$ after treatment, corresponding to a reduction in the extracellular space in agreement with a transient phenomenon, the cell swelling, which had already been observed in our study using confocal microscopy on in vitro CDDP-treated SKOV3.ip cells. In other words, CDDP also exerted on in vivo SKOV3.ip xenografts a cytostatic (but not a cytotoxic) effect similar to that induced on SKOV3.ip cells. These observed changes in the ADC values of CDDP-treated SKOV3.ip xenografts seem to go in the opposite direction compared with those observed in the ADC values of patient treated with a platinum-based chemotherapy (Kyriazi et al, 2011; Sala et al, 2012). This apparent discrepancy was likely due to the fact that our measurements were performed at really early times after the start of treatment (24-48 h), which snapshotted a tumour situation very different from that one could find in patients at the end of the first (Kyriazi et al, 2011) or third cycle of therapy (Sala et al, 2012). Another reason can be found in the nature of our cells (SKOV3), which are derived from a patient who had already been treated with a platinum-based chemotherapy. In fact, ADC measurements performed at the end of the CDDP treatment did not show any alterations neither in the ADC mean value and distribution nor changes in cell viability (data not shown).

We performed a full set of analyses separating the component at low- $b$-value from the perfusion-free diffusion, to monitor the signal decay in vascular and tissue compartments, respectively. We could not detect any differences in the VSF of our xenografts confirming the hypothesis that, when acting as a cytostatic agent, cisplatin does not induce any relevant effect on tumour vasculature. Although VSF is not a direct biomarker of therapy response, this parameter could be considered as an index of unaltered vasculature within the limit of the experimental measure method.

As a further refinement, a bi-exponential function might be used, as described by Le Bihan et al (1988) for the IVIM method, which could replace the VSF method, to calculate flow-sensitive $\mathrm{ADC}$ from DWI at low $b$ values.

\section{CONCLUSIONS}

Compared with the parental SKOV3 cell line, the in vivo passaged SKOV3.ip cell variant exhibited enhanced in vivo tumorigenicity in SCID mice, higher HER2 overexpression, increased PCho level but very similar in vitro cell proliferation curves.

The cytostatic effects exerted by $5 \mu \mathrm{m}$ cisplatin were associated with a metabolic shift towards accumulation of neutral lipids organised in cytosolic bodies. No changes were instead induced by the drug on the tCho profile of in vitro cultured SKOV3.ip cells nor in that of in vivo SKOV3.ip xenografts.

DW MR imaging is a potentially useful imaging modality for monitoring the response of a HER2-overexpressing ovarian cancer model to the cytostatic action of cisplatin.

\section{ACKNOWLEDGEMENTS}

We acknowledge partial support by: Associazione Italiana per la Ricerca sul Cancro (AIRC) 2007-2010 (PIs: FP and EI); Integrated Oncology Program RO 06.5/N.ISS/Q0, Oncology Program OncOrd 37/07/N. ISS/70CF/4 and Special Program Alleanza Contro il Cancro 2006, ACC3-AC5/D, Ministry of Health, Italy (PI: FP); Accordo di Collaborazione Italia-USA ISS/530F/0F29 (PI: FP and EI); AIRC
2009-2011, IG N. 9147 and AIRC IG 129762012 (PI: DM) and Programma Oncotecnologico ISS/13ONC/5 (PI: EI). We are grateful to Dr Andrea Rodomonte for the thermo-gravimetric analyses and Massimo Giannini for maintenance of the MR equipment.

\section{CONFLICT OF INTEREST}

The authors declare no conflict of interest.

\section{REFERENCES}

Abalsamo L, Spadaro F, Bozzuto G, Paris L, Cecchetti S, Lugini L, Iorio E, Molinari A, Ramoni C, Podo F (2012) Inhibition of phosphatidylcholinespecific phospholipase $\mathrm{C}$ results in loss of mesenchymal traits in metastatic breast cancer cells. Breast Cancer Res 14: R50.

Aboagye EO, Bhujwalla ZM (1999) Malignant transformation alters membrane choline phospholipid metabolism of human mammary epithelial cells. Cancer Res 59: 80-84.

Beloueche-Babari M, Chung YL, Al-Saffar NM, Falck-Miniotis M, Leach MO (2010) Metabolic assessment of the action of targeted cancer therapeutics using magnetic resonance spectroscopy. Br J Cancer 102: 1-7.

Bhakoo KK, Williams SR, Florian CL, Land H, Noble MD (1996) Immortalization and transformation are associated with specific alterations in choline metabolism. Cancer Res 56: 4630-4635.

Blankenberg FG, Storrs RW, Naumovski L, Goralski T, Spielman D (1996) Detection of apoptotic cell death by proton nuclear magnetic resonance spectroscopy. Blood 87: 1951-1956.

Canese R, Pisanu ME, Mezzanzanica D, Ricci A, Paris L, Bagnoli M, Valeri B, Spada M, Venditti M, Cesolini A, Rodomonte A, Giannini M, Canevari S, Podo F, Iorio E (2012) Characterisation of in vivo ovarian cancer models by quantitative $1 \mathrm{H}$ magnetic resonance spectroscopy and diffusionweighted imaging. NMR Biomed 25: 632-642.

Carter JS, Koopmeiners JS, Kuehn-Hajder JE, Metzger GJ, Lakkadi N, Downs Jr LS, Bolan PJ (2013) Quantitative multiparametric MRI of ovarian cancer. J Magn Reson Imaging 38: 1501-1509.

Cheng JC, Qiu X, Chang HM, Leung PC (2013) HER2 mediates epidermal growth factor-induced down-regulation of E-cadherin in human ovarian cancer cells. Biochem Biophys Res Commun 434: 81-86.

Day SE, Kettunen MI, Gallagher FA, Hu DE, Lerche M, Wolber J, Golman K, Ardenkjaer-Larsen JH, Brindle KM (2007) Detecting tumor response to treatment using hyperpolarized $13 \mathrm{C}$ magnetic resonance imaging and spectroscopy. Nat Med 13: 1382-1387.

Delikatny EJ, Chawla S, Leung DJ, Poptani H (2011) MR-visible lipids and the tumor microenvironment. NMR Biomed 24: 592-611.

Delikatny EJ, Cooper WA, Brammah S, Sathasivam N, Rideout DC (2002) Nuclear magnetic resonance-visible lipids induced by cationic lipophilic chemotherapeutic agents are accompanied by increased lipid droplet formation and damaged mitochondria. Cancer Res 62: 1394-1400.

Di Vito M, Lenti L, Knijn A, Iorio E, D'Agostino F, Molinari A, Calcabrini A, Stringaro A, Meschini S, Arancia G, Bozzi A, Strom R, Podo F (2001) 1H NMR-visible mobile lipid domains correlate with cytoplasmic lipid bodies in apoptotic T-lymphoblastoid cells. Biochim Biophys Acta 1530: 47-66.

Duarte IF, Lamego I, Marques J, Marques MP, Blaise BJ, Gil AM (2010) Nuclear magnetic resonance (NMR) study of the effect of cisplatin on the metabolic profile of MG-63 osteosarcoma cells. J Proteome Res 9: 5877-5886.

Garrett MD, Workman P (1999) Discovering novel chemotherapeutic drugs for the third millennium. Eur J Cancer 35: 2010-2030.

Glunde K, Bhujwalla ZM, Ronen SM (2011a) Choline metabolism in malignant transformation. Nat Rev Cancer 11: 835-848.

Glunde K, Jiang L, Moestue SA, Gribbestad IS (2011b) MRS and MRSI guidance in molecular medicine: targeting and monitoring of choline and glucose metabolism in cancer. NMR Biomed 24: 673-690.

Glunde K, Raman V, Mori N, Bhujwalla ZM (2005) RNA interferencemediated choline kinase suppression in breast cancer cells induces differentiation and reduces proliferation. Cancer Res 65: 11034-11043.

Griffiths JR, McSheehy PM, Robinson SP, Troy H, Chung YL, Leek RD, Williams KJ, Stratford IJ, Harris AL, Stubbs M (2002) Metabolic changes detected by in vivo magnetic resonance studies of HEPA-1 wild-type tumors 
and tumors deficient in hypoxia-inducible factor-1beta (HIF-1beta): evidence of an anabolic role for the HIF-1 pathway. Cancer Res 62: 688-695.

Hakumäki JM, Poptani H, Sandmair AM, Yla-Herttuala S, Kauppinen RA (1999) 1H MRS detects polyunsaturated fatty acid accumulation during gene therapy of glioma: implications for the in vivo detection of apoptosis. Nat Med 5: 1323-1327.

Iorio E, Di Vito M, Spadaro F, Ramoni C, Lococo E, Carnevale R, Lenti L, Strom R, Podo F (2003) Triacsin C inhibits the formation of $1 \mathrm{H}$ NMRvisible mobile lipids and lipid bodies in HuT 78 apoptotic cells. Biochim Biophys Acta 1634: 1-14.

Iorio E, Mezzanzanica D, Alberti P, Spadaro F, Ramoni C, D’Ascenzo S, Millimaggi D, Pavan A, Dolo V, Canevari S, Podo F (2005) Alterations of choline phospholipid metabolism in ovarian tumour progression. Cancer Res 65: 9369-9376.

Iorio E, Ricci A, Bagnoli M, Pisanu ME, Castellano G, Di Vito M, Venturini E, Glunde K, Bhujwalla ZM, Mezzanzanica D, Canevari S, Podo F (2010) Activation of phosphatidylcholine cycle enzymes in human epithelial ovarian cancer cells. Cancer Res 70: 2126-2135.

Koh DM, Collins DJ (2007) Diffusion-weighted MRI in the body: applications and challenges in oncology. AJR Am J Roentgenol 188: 1622-1635.

Kurhanewicz J, Vigneron DB, Hricak H, Narayan P, Carroll P, Nelson SJ (1996) Three-dimensional H-1 MR spectroscopic imaging of the in situ human prostate with high $(0.24-0.7-\mathrm{cm} 3)$ spatial resolution. Radiology 198: 795-805

Kyriazi S, Collins DJ, Messiou C, Pennert K, Davidson RL, Giles SL, Kaye SB, Desouza NM (2011) Metastatic ovarian and primary peritoneal cancer: assessing chemotherapy response with diffusion-weighted MR imaging-value of histogram analysis of apparent diffusion coefficients. Radiology 261: 182-192.

Lafky JM, Wilken JA, Baron AT, Maihle NJ (2008) Clinical implications of the ErbB/epidermal growth factor (EGF) receptor family and its ligands in ovarian cancer. Biochim Biophys Acta 1785: 232-265.

Le Bihan D, Breton E, Lallemand D, Aubin ML, Vignaud J, Laval-Jeantet M (1988) Separation of diffusion and perfusion in intravoxel incoherent motion MR imaging. Radiology 168: 497-505.

Mirbahai L, Wilson M, Shaw CS, McConville C, Malcomson RD, Griffin JL, Kauppinen RA, Peet AC (2011) 1H magnetic resonance spectroscopy metabolites as biomarkers for cell cycle arrest and cell death in rat glioma cells. Int J Biochem Cell Biol 43: 990-1001.

Mirbahai L, Wilson M, Shaw CS, McConville C, Malcomson RD, Kauppinen RA, Peet AC (2012) Lipid biomarkers of glioma cell growth arrest and cell death detected by $1 \mathrm{H}$ magic angle spinning MRS. NMR Biomed 25: 1253-1562.

Morse DL, Raghunand N, Sadarangani P, Murthi S, Job C, Day S, Howison C, Gillies RJ (2007) Response of choline metabolites to docetaxel therapy is quantified in vivo by localized (31)P MRS of human breast cancer xenografts and in vitro by high-resolution (31)P NMR spectroscopy of cell extracts. Magn Reson Med 58: 270-280.

Murphy PS, Viviers L, Abson C, Rowland IJ, Brada M, Leach MO, Dzik-Jurasz AS (2004) Monitoring temozolomide treatment of low-grade glioma with proton magnetic resonance spectroscopy. Br J Cancer 90: 781-786.

Nardo G, Favaro E, Curtarello M, Moserle L, Zulato E, Persano L, Rossi E, Esposito G, Crescenzi M, Casanovas O, Sattler U, Mueller-Klieser W, Biesalski B, Thews O, Canese R, Iorio E, Zanovello P, Amadori A, Indraccolo S (2011) Glycolytic phenotype and AMP kinase modify the pathologic response of tumor xenografts to VEGF neutralization. Cancer Res 71: 4214-4225.

Negendank W (1992) Studies of human tumors by MRS: a review. NMR Biomed 5: 303-324.

Ohta T, Ohmichi M, Shibuya T, Takahashi T, Tsutsumi S, Takahashi K, Kurachi H (2012) Gefitinib (ZD1839) increases the efficacy of cisplatin in ovarian cancer cells. Cancer Biol Ther 13: 408-416.

Pan X, Wilson M, McConville C, Arvanitis TN, Griffin JL, Kauppinen RA, Peet AC (2013) Increased unsaturation of lipids in cytoplasmic lipid droplets in DAOY cancer cells in response to cisplatin treatment. Metabolomics 9: 722-729.

Paris L, Cecchetti S, Spadaro F, Abalsamo L, Lugini L, Pisanu ME, Iorio E, Natali PG, Ramoni C, Podo F (2010) Inhibition of phosphatidylcholinespecific phospholipase $\mathrm{C}$ downregulates HER2 overexpression on plasma membrane of breast cancer cells. Breast Cancer Res 12: R27.

Payne GS, Leach MO (2006) Applications of magnetic resonance spectroscopy in radiotherapy treatment planning. Br J Radiol. 79 S16-S26.

Podo F (1999) Tumour phospholipid metabolism. NMR Biomed 12: 413-439.
Podo F, Canevari S, Canese R, Pisanu ME, Ricci A, Iorio E (2011) Magnetic resonance evaluation of response to targeted treatment in cancer cells. NMR Biomed 24: 648-672.

Podo F, Ferretti A, Knijn A, Zhang P, Ramoni C, Barletta B, Pini C, Baccarini S, Pulciani S (1996) Detection of phosphatidylcholine-specific phospholipase C in NIH-3T3 fibroblasts and their H-ras transformants: NMR and immunochemical studies. Anticancer Res 16: 1399-1412.

Proietti E, Belardelli F, Carpinelli G, Di Vito M, Woodrow D, Moss J, Sestili P, Fiers W, Gresser I, Podo F (1988) Tumor necrosis factor alpha induces early morphologic and metabolic alterations in Friend leukemia cell tumors and fibrosarcomas in mice. Int J Cancer 42: 582-591.

Provencher SW (1993) Estimation of metabolite concentrations from localized in vivo proton NMR spectra. Magn Reson Med 30: 672-679.

Ramoni C, Spadaro F, Barletta B, Dupuis ML, Podo F (2004) Phosphatidylcholine-specific phospholipase C in mitogen-stimulated fibroblasts. Exp Cell Res 299: 370-382.

Ronen SM, Jackson LE, Beloueche M, Leach MO (2001) Magnetic resonance detects changes in phosphocholine associated with Ras activation and inhibition in NIH 3T3 cells. Br J Cancer 84: 691-696.

Sala E, Kataoka MY, Priest AN, Gill AB, McLean MA, Joubert I, Graves MJ, Crawford RA, Jimenez-Linan M, Earl HM, Hodgkin C, Griffiths JR, Lomas DJ, Brenton JD (2012) Advanced ovarian cancer: multiparametric MR imaging demonstrates response- and metastasis-specific effects. Radiology 263: 149-159.

Sala E, Priest AN, Kataoka M, Graves MJ, McLean MA, Joubert I, Griffiths JR, Crawford RA, Jimenez-Linan M, Earl HM, Brenton JD, Lomas DJ (2010) Apparent diffusion coefficient and vascular signal fraction measurements with magnetic resonance imaging: feasibility in metastatic ovarian cancer at 3 Tesla: technical development. Eur Radiol 20: 491-496.

Sala E, Rockall AG, Freeman SJ, Mitchell DG, Reinhold C (2013) The added role of MR imaging in treatment stratification of patients with gynecologic malignancies: what the radiologist needs to know. Radiology 266: 717-740.

Serkova NJ, Brown MS (2012) Quantitative analysis in magnetic resonance spectroscopy: from metabolic profiling to in vivo biomarkers. Bioanalysis 4: 321-341.

Sharma U, Baek HM, Su MY, Jagannathan NR (2011) In vivo 1H MRS in the assessment of the therapeutic response of breast cancer patients. NMR Biomed 24: 700-711.

Spadaro F, Ramoni C, Mezzanzanica D, Miotti S, Alberti P, Cecchetti S, Iorio E, Dolo V, Canevari S, Podo F (2008) Phosphatidylcholine-specific phospholipase $\mathrm{C}$ activation in epithelial ovarian cancer cells. Cancer Res 68: 6541-6549.

Sperka T, Wang J, Rudolph KL (2012) DNA damage checkpoints in stem cells, ageing and cancer. Nat Rev Mol Cell Biol 13: 579-590.

Thoeny HC, Ross BD (2010) Predicting and monitoring cancer treatment response with diffusion-weighted MRI. J Magn Reson Imaging 32: 2-16.

Tomayko MM, Reynolds CP (1989) Determination of subcutaneous tumor size in athymic (nude) mice. Cancer Chemother Pharmacol 24: 148-154.

Vaughan S, Coward JI, Bast Jr. RC, Berchuck A, Berek JS, Brenton JD, Coukos G, Crum CC, Drapkin R, Etemadmoghadam D, Friedlander M, Gabra H, Kaye SB, Lord CJ, Lengyel E, Levine DA, McNeish IA, Menon U, Mills GB, Nephew KP, Oza AM, Sood AK, Stronach EA, Walczak H, Bowtell DD, Balkwill FR (2011) Rethinking ovarian cancer: recommendations for improving outcomes. Nat Rev Cancer 11: 719-725.

Wakefield JC, Downey K, Kyriazi S, deSouza NM (2013) New MR techniques in gynecologic cancer. AJR Am J Roentgenol 200: 249-260.

Wang D, Lippard SJ (2005) Cellular processing of platinum anticancer drugs. Nat Rev Drug Discov 4: 307-320.

Yamashita Y, Kumabe T, Higano S, Watanabe M, Tominaga T (2009) Minimum apparent diffusion coefficient is significantly correlated with cellularity in medulloblastomas. Neurol Res 31: 940-946.

Yu D, Wolf JK, Scanlon M, Price JE, Hung MC (1993) Enhanced c-erbB-2/neu expression in human ovarian cancer cells correlates with more severe malignancy that can be suppressed by E1A. Cancer Res 53: 891-898.

This work is published under the standard license to publish agreement. After 12 months the work will become freely available and the license terms will switch to a Creative Commons AttributionNonCommercial-Share Alike 3.0 Unported License.

\section{Supplementary Information accompanies this paper on British Journal of Cancer website (http://www.nature.com/bjc)}

